\title{
The Primacy of L1-Based Cohesive Devices Over the Organization of Ideas in the Spoken English of Chinese EFL Learners
}

\author{
Sulaiman Alrabah ${ }^{1} \&$ Shu-hua $\mathrm{Wu}^{1}$ \\ ${ }^{1}$ Language Center, College of Business Studies, Public Authority for Applied Education and Training, Kuwait \\ Correspondence: Shu-hua Wu, Language Center, College of Business Studies, Public Authority for Applied \\ Education and Training, Kuwait. E-mail: wu104ohio@yahoo.com.tw
}

Received: January 16, 2019 Accepted: February 12, 2019 Online Published: March 2, 2019

doi:10.5539/ijel.v9n2p373 URL: https://doi.org/10.5539/ijel.v9n2p373

\begin{abstract}
L1 influence research on L2 learners' spoken performance has focused on learners' use of L1-based cohesive devices and propositional organization. The problem in these studies was that even though L2 learners were using L1-based cohesive devices, they were not making any grammatical or pronunciation errors, but their L2 speech patterns were not consistent with native speaker standards. This study investigated the ways in which 6 Chinese English as a foreign language (EFL) learners were influenced by their L1-based cohesive devices and organization of ideas during 30 hours of face-to-face interactions with 2 English native speakers. Data analysis involved transforming the transcribed data of interactions into a system of codes and categories (Corbin \& Strauss, 2015), and the Excel software was used to generate the means, percentages, and ranks of different categories. Data analysis determined that Chinese L1-based cohesive devices and organization of ideas were manifested in the 6 Chinese participants' speech as a coherent system of communication. Moreover, the researchers found that the most frequently-used L1-based cohesive device in the Chinese students' L2 speech was the use of connectors which were employed to "add" new points to the speakers' arguments. Implications for pedagogy included action research projects to scrutinize the introduction of a series of communicative tasks in the classroom that utilize scaffolding to highlight L1-L2 differences. The aim of these tasks is to raise students' consciousness and help them "notice the gap" between L1-L2 discourse systems in the use of cohesive devices and organization of ideas.
\end{abstract}

Keywords: L1 influence on L2 use, L1-based cohesive devices, L1-based organization of ideas, scaffolding techniques, discourse analysis, second language acquisition, cross-cultural communication

\section{Introduction}

Within the fields of Second Language Acquisition (SLA) and language pedagogy, the influence of learners' first language (L1) on the second language (L2) continues to stir interest and controversy among researchers (Golden, Jarvis, \& Tenfjord, 2017; Ritchie \& Bhatia, 2013; Yu \& Odlin, 2016). Researchers with different theoretical perspectives continue to speculate on the reasons that lead learners to exhibit L1 influence in their L2 performance. Moreover, L1 influence research has been focused on multiple areas of second language performance. Early studies focused on the influence of morpho-syntactic features of the L1 on the learner's L2 spoken and written performance (e.g., Rutherford, 1983). More recently, SLA researchers have moved beyond the sentence level to focus on the influence of L1 on the pragmatic (e.g., Bardovi-Harlig \& Hartford, 2016) and discourse features of the L2 (e.g., Connor, Nagelhout, \& Rozycki, 2008). Researchers turned their interests to investigate L1 influence on the L2 in extended chunks of language ranging from the performance of the most rudimentary requests and compliments to more elaborate discourse features such as cohesive devices and the organization of argument structure. Research within SLA studies has, thus, made great strides in its scope and interest to move from the basic syntactic structures to the most intricate discourse features of a learner's L1 in the L2. Explanations of the reasons behind L1 influence in L2 learners' performance varied according to researchers' theoretical orientations. For example, Selinker and Rutherford (2014) proposed that L1 influence phenomenon occurred consistently among second language learners due to erroneous "assumptions of L1-L2 equivalence". Within this perspective, the learner perceives similarities between L1 and L2 and, therefore, assumes they are equal and commits errors in using L2. The learner is said to simply make an erroneous hypothesis that both his/her L1 and L2 are equal and therefore, he/she can use the L1 and L2 interchangeably at all times. These erroneous "interlingual identifications" were further explained as the judgement that something in the native language and something in the target 
language are similar. For example, when an L2 learner faces a gap in L2 knowledge, then the ideal strategy is to use L1 knowledge (Odlin \& Yu, 2016).

Furthermore, L1 influence research on Chinese learners' spoken performance has focused on learners' use of L1-based cohesive devices and propositional organization. The problem in these studies was that even though they were using L1-based cohesive devices, Chinese second language learners were not making any grammatical or pronunciation errors, but their L2 speech patterns were not consistent with English native speaker baseline data. For example, Rutherford (1983) pointed out that Chinese ESL learners were consistently influenced by their L1 topic-comment sentence structure in their informative and discursive patterns in the L2. This reliance on topic-comment sentence structure led them to produce sentences that varied from the dominant subject-predicate structure in English. Moreover, Scollon, Scollon, and Jones (2012) suggested that potential miscommunication may take place when a Chinese learner utilized L1 discourse strategies and cohesive devices in the L2 context that led to different interactional consequences from those commonly anticipated in the L1 context. However, there is an increasing awareness that research on L1 influence may need to take into consideration the fact that languages other than English may possess different principles of discourse organization and different uses of cohesive devices (Mohamed-Sayidina, 2010). After conducting a meta-analysis study of 50 investigations of Arab students' English writing which exhibited clear cases of transfer of L1-based cohesive devices, Mohamed-Sayidina (2010) made a hypothesis stating that "the Arab students' English compositions use a predominantly additive mode of propositional development" (p. 253). She further hypothesized that due to the fact that Arabic is an "additive" language, Arab ESL students used cohesive devices to "add" new points to their arguments in their English writing. Mohamed-Sayidina showed that L1 influence can impact the ways L2 learners organize their ideas and connect them with cohesive devices.

Thus, there was a need to conduct the present study on the L2 speech of 6 Chinese participants as they interacted with 2 English native speakers to explore the possibility that they are relying on L1-based principles of using cohesive devices and organization of ideas in their spoken English. The purpose of the study was, therefore, to investigate whether, and if so, to what extent a different mode of propositional articulation of oral Chinese than English influenced the Chinese learners' spoken performance in English as a second language. In sum, the study was conducted to investigate the extent of the influence of L1-based cohesive devices and organization of ideas in the 6 Chinese learners' speech while talking in English with the 2 English native speakers. Data analysis was conducted to answer the following research questions:

1) What were the L1-based cohesive devices employed by the 6 Chinese EFL learners during their interactions with the 2 English native speakers?

2) What were the L1-based modes of organization of ideas employed by the 6 Chinese EFL learners during their interactions with the 2 English native speakers?

The researchers focused on spoken discourse to understand the different manifestations of L1 influence in the L2 speech of the 6 Chinese participants. The Chinese learners were each asked to participate in a series of 60 minute face-to-face interactions with 2 adult native speakers of English who volunteered to participate in the study.

\section{Review of the Literature}

Three major bodies of research generated evidence-based investigations of L1 influence in L2 learners' speech. First, analysis of cross-cultural communication focused on encounters between native speakers of English and L2 users in which L1 influence led to situations where there was potential for miscommunication (e.g., Scollon et al, 2012). Second, analysis of social factors viewed L1 influence as determined by external factors such as the learner's awareness of social conventions (e.g., Odlin, 1989; Pierce, 1995). Third, analysis of cognitive processing concerned L1 influence as an internal process within the L2 learner (e.g., Selinker \& Rutherford, 2014). Ideally, L1 influence research can offer a comprehensive explanation that moves beyond a listing of L1-based discourse features into a socio-cognitive framework that is not only interested in describing the social patterns of language use, but also the analytic reasoning done by the $\mathrm{L} 2$ learners as reflected in the organization of their utterances in the L2 context. Moreover, a comprehensive understanding of the L1 influence must also take into account that L1 influence takes place as a result of the interaction between linguistic, social, and cultural factors in L2 learners' spoken performance (Lantolf \& Poehner, 2014). This review is, therefore, organized into three sections. The first section described L1 influence in cross-cultural studies that focused on miscommunication potential between native speakers of English and Chinese EFL learners. The second section focused on studies of L1 influence that impacted learners of English as they moved into the target cultures where English became the dominant language of communication in those societies. The review concludes in the third section which described second language acquisition studies that investigated the role of L1 influence in language learning. 


\subsection{L1 Influence in Cross-Cultural Communication}

Several research studies have focused on the differences between Chinese and English spoken discourses (Rutherford, 1983; Scollon et al., 2012). For example, Rutherford interpreted Chinese ESL learners' heavy reliance on topic-comment sentences as they used English as L1 influence of Chinese which is a topic-prominent language. He proposed that Chinese learners were unconsciously organizing information following the sentence structure of their L1. More recently, Li and Yang (2014) conducted a study on the L1 influence of Chinese topic prominence to L2 English. They concluded that topic-comment structures gradually disappeared from Chinese ESL learners' speech as they gained more proficiency in English. Meanwhile, researchers interested in cross-cultural communication, focused on the socio-cultural factors that may lead to misunderstandings between people who come from different language backgrounds and who are using English as a tool for communication. Within studies of cross-cultural communication, Scollon et al. (2012) described encounters that resulted in miscommunication in business meetings between Chinese and American businessmen. These encounters led to the unfortunate stereotypes of the "inscrutable" Asian, or the frank and rude "westerner." The primary method taken in L1 influence studies was to investigate the L2 learners' use of L1 discourse patterns and norms of interaction to the L2 context. In these studies, Scollon et al. (2012) suggested that miscommunication took place when an L2 learner utilized L1 discourse strategies and patterns in the L2 context that have resulted in different interactional consequences from those commonly anticipated in the L1 context. In other words, miscommunication potential happens because different cultures have different notions of what it means to be communicatively effective. As such, L1 influence studies usually deal with analyzing situations in which both language and culture are at play. The learner's erroneous use of the L2 in different L2 interactional contexts offers the analyst insights about the interplay between linguistic and cultural conventions in L2 spoken and written performance.

However, there is a growing awareness that research on $\mathrm{L} 1$ influence needs to take into consideration the fact that languages other than English may possess different principles of discourse organization and different uses of cohesive devices in their respective cultures. For example, based on a meta-analysis of 50 studies on Arab students' transfer of cohesive devices, Mohamed-Sayidina (2010) hypothesized that "the Arab students' English compositions use a predominantly additive mode of propositional development" (p. 253). She further suggested that due to the fact that Arabic is an "additive" language, Arab ESL students used cohesive devices to "add" new points to their arguments in their English writing. Mohamed-Sayidina showed that L1 influence can impact the ways L2 learners organize their ideas and connect them with cohesive devices. More research studies are thus needed to explore L1 influence on speakers from other language backgrounds such as Chinese, Japanese, and Turkish to determine the effects of L1 principles of discourse organization in cohesive devices and introducing new ideas in casual conversation.

\subsection{L1 Influence within the Social Perspective}

Socially-oriented studies have attributed more influence to the social setting in determining the causes behind L1 influence. Studies that investigated L1 influence from a social perspective started with the assumption that using the L2 can be a form of social action by the language learner to express a sense of social identity. (e.g., Odlin, 1989; Peirce, 1995). Socially-oriented researchers have, therefore, focused on how L2 discourse is used by L2 learners to achieve a variety of social-pragmatic functions. They have also focused their analyses on the ways in which language use is closely related to social identity and face relations (e.g., Scollon et al., 2012). According to these researchers, the causes behind L1 influence are mainly external to the learner and are related to the ways in which common discourse practices in the speech community are responsible for marginalizing language learners away from the mainstream of society through their use of L1-based patterns of language use in L2 contexts. For example, Odlin (1989) studied the causes behind L1 influence in Ireland. He noted that some Irish English idioms and expressions that could only have come from Gaelic constituted a social phenomenon and that indicated membership in the Irish speech community. Furthermore, Peirce (1995) accounted for the occurrence of L1 influence as an outcome of the social practices within a given speech community. Working within the Canadian setting where English is the primary language, Peirce showed that there was a close link between the patterns of language use employed by second language learners and their overall sense of social identity. In a related study in the U.S., MacKay and Wong (1996) showed that the major coping strategy developed by their 4 Chinese subjects was to assume "multiple identities" that fit the various discourses that confronted them in the classroom, the playground, and the street. According to these researchers (e.g., MacKay \& Wong, 1996; Odlin, 1989; Peirce, 1995), L1 influence may be caused by social and cultural factors that are mainly "external" to the learner and may be related to the ways in which common mainstream patterns of language use are responsible for socially "marginalizing" the second language learner. 


\subsection{L1 Influence in SLA Studies}

Second language acquisition (SLA) aimed to account for all the processes that govern second language learning. Analysis of cognitive processing concerned L1 influence as an internal process within the L2 learner (e.g., Selinker \& Rutherford, 2014). SLA researchers who investigated L1 influence looked at how the language learner used his/her knowledge of the linguistic properties of the L1 to perform various phonological, morphological, syntactic, and lexical functions in the L2 (e.g., Pasquarella, Chen, Lam, Luo, \& Ramirez, 2011). Moving beyond the sentence level, L1 influence research targeted the L1-based discourse patterns of learner language in order to show how they utilized the L1-based cohesive devices to link sentences in the L2 (Connor et al., 2008). In order to investigate L1 influence, SLA researchers collected interactional data and concentrated on identifying the discourse patterns produced by the L2 learners that were deviant from native speaker norms. SLA studies have concluded that L1 influence was a result of mistaken judgements by L2 learners about the similarities between L1 and L2 (Selinker \& Rutherford, 2014).

There was, thus, a need for the present study to target L1 influence from Chinese to English in the area of cohesive devices and organization of ideas in face-to-face interactions between Chinese EFL learners and native speakers of English. The purpose of the study was to investigate how 6 Chinese EFL learners were influenced by their L1 discourse features to accomplish a variety of communication goals in the L2 interactional context.

\section{Methodology}

Data collection involved recorded observations of casual conversations of face-to-face interactions between the Chinese participants and the native speakers of English. Interviews following the interactions targeted Chinese EFL students' L1-based cohesive devices and organization of ideas. Data analysis methods included coding and categorizing recurring patterns of L1-based influence as well as using the Excel software to generate means, percentages, and ranks. Data display included 3 tables. Table 1 displayed the category system of cohesive devices and organization of ideas. Table 2 displayed the frequency of L1-based cohesive devices, and Table 3 included the frequency of L1-based organization of ideas. The numerical table displays were supplemented with selected excerpts from the transcripts to demonstrate the subcategories under the two categories of cohesive devices and organization of ideas.

\subsection{Sampling and Participants}

The 6 Chinese participants came from Taiwan and were studying at a university in Kuwait. The 2 native speakers of English were volunteers in a program that promoted English language study and cultural understanding. The program arranged for weekly conversations with English native speakers for increasing EFL learners' speaking fluency and listening comprehension. The researchers distributed among the participants in the program a solicitation letter explaining the purpose of the research along with assurances about the confidentiality and anonymity of the names of the participants. They were also assured that they could drop out of the study at any point they felt without the need to explain their reasons. Upon agreeing to partake in the study, the 8 participants were asked to sign letters of informed consent that the data will only be used for the purpose of the research.

\subsection{Data Collection}

Data collection consisted primarily of audio-taped interactional sessions between the 6 Chinese participants and the 2 English native speakers (approximately 30 hours). Each of the Chinese participants was scheduled to interact with a different English native speaker spaced at intervals of about one to two weeks. The researchers focused on L1-based discourse patterns in the L2 speech of the Chinese participants. In order to facilitate the data collection process, the 30-hour audiotaped interactional sessions were transcribed by the researchers, and then were divided into six computer files. Each file name was placed under the name of one of the six Chinese participants. After each interactional session, interviews were conducted with the Chinese participants to gain their perspectives on the L1 influence patterns that were produced by them in the course of the interactions.

\subsection{Data Analysis}

Data analysis methods consisted of the use of the Excel software by the researchers to generate the frequencies of use, means, percentages, and rankings of each discourse category the 6 Chinese participants employed during their face-to-face interactions with the 2 English native speakers. Tables 1, 2, and 3 were generated to display the descriptive statistics that were conducted on the data of the interactions. Table 1 was devoted to the cohesive devices and Table 2 was devoted to idea organization. Moreover, data analysis focused on transforming the data of the interactions into a system of codes and categories (Corbin \& Strauss, 2015; Gibbs, 2018). The researchers adopted a three-step approach to the analysis of transcript data: (a) identifying and classifying the 6 Chinese students' commonly-used discourse patterns that have L1 influence, (b) confirming L1 influence by comparing 
between the learners' L2 performance and the patterns of the first language, and (c) triangulation of identified L1 influence patterns by seeking evidence from the data that was produced by other participants in the interactions. Triangulation of some patterns also involved seeking evidence from the available sources of learner data such as the interviews and the researcher's field-notes. Triangulation thus involved putting the same pattern on hold to see whether the other participants or the same participant employed the same pattern in other interactions. Moreover, the interviews and the researchers' field-notes were treated as supplementary sources of data that provided confirming/disconfirming evidence on the use of some of the patterns included in the final step of the data analysis. Assignment of learner utterances to specific discourse categories was also conducted independently by the co-author and reached a high degree of consistency (94\%).

\section{Results}

Table 1 displayed the two major categories of L1 cohesive devices and organization of ideas and their subcategories as observed in the data of the interactions between the 6 Chinese participants and 2 English speakers.

Table 1. The L1-based category system of cohesive devices and organization of ideas

\begin{tabular}{lll}
\hline Item & Major Categories & Subcategories \\
\hline I & Cohesive Devices & Conjunction with “And" \\
& & Disjunction with "But" \\
& Referencing \\
& Rhetorical Questions \\
\hline II & Organization of Ideas & Stating One's Position at the End \\
& Topic-Comment Word Order \\
& Recalling \\
& Revisiting \\
\hline
\end{tabular}

There were two main findings on L1-based cohesive devices and organization of ideas in the 6 Chinese participants' L2 speech. The first finding was that the Chinese participants' L2 speech was primarily influenced by the use of the first two subcategories of cohesive devices: conjunction with "and," and disjunction with "but". In other words, the 6 Chinese participants were using conjunctions and disjunctions to advance their arguments and introduce new ideas in their speech. L1 influence from Chinese to English speech was, therefore, "additive" in nature and worked in a similar way to Mohamed-Sayidina's (2010) hypothesis about Arabic being an "additive" language. The researchers listed two more subcategories that were considered cohesive devices that supported the "additive" nature of Chinese speech. The third subcategory, "referencing", was a cohesive devise commonly used by the Chinese participants to support their opinions by referring to others' words and opinions (i.e., they say). Moreover, the fourth subcategory "rhetorical questions" was used to stress points and add emphasis by calling listeners' attention to their speech. Data analysis determined that the primary tool that the Chinese participants relied on was the use of these four subcategories of cohesive devices to add to their arguments and to present new ideas.

The second finding was that the Chinese speakers' ideas and argument structures played a secondary role to the cohesive devices due to their reliance on cohesive devices to add points to their speech. There were four subcategories in the category of organization of ideas. First, the Chinese speakers invariably reached their conclusions (i.e., positions) near the end of their conversations. Second, the basic Chinese word structure in sentences followed a topic-comment word order. Third, when introducing a new idea, the Chinese speakers frequently "recalled" something from the past typically by preceding an utterance with a familiar phrase "when I was young," or some other words that indicated past events. Fourth, at some point in any given conversation, a Chinese speaker would "revisit" a point he/she already mentioned for more elaboration.

\subsection{L1 Influence on the Use of Cohesive Devices}

Numerical data supported the prevalence of cohesive devices in the 6 Chinese speakers' L2 speech. Table 2 displayed the frequencies, means, percentages, and ranks of the 6 Chinese participants both as a group and as individuals for each subcategory of cohesive devices. 
Table 2. Frequency of L1-based cohesive devices

\begin{tabular}{lcccc}
\hline Cohesive Devices & Frequency & M & Percentage & Rank \\
\hline Conjunction with "And" & 1277 & 212.83 & $60.21 \%$ & 1 \\
Disjunction with "But" & 598 & 99.67 & $28.19 \%$ & 2 \\
Referencing & 188 & 31.33 & $8.86 \%$ & 3 \\
Rhetorical Questions & 58 & 9.67 & $2.73 \%$ & 4 \\
\hline Total & 2121 & 353.50 & - & - \\
\hline
\end{tabular}

First, conjunction with "and" was the most frequently used subcategory employed by the 6 Chinese participants. It ranked at number 1 reaching a total of 1,277 occurrences with $60.21 \%$ of frequency of use among the Chinese participants as a group. Similarly, individual participants used conjunction with "and" most frequently with nearly 213 occurrences on average. Second, disjunction with "but" came second and was commonly used by the participants but to a lesser extent than conjunction with "and". Disjunction with "but" reached a total of 598 occurrences with $28.19 \%$ of frequency of use as a group in the 6 Chinese participants speech. Individual participants used disjunction with "but" reaching nearly 100 occurrences on average. These two subcategories constituted among them $88.40 \%$ of frequency of use in cohesive devices. This meant that the 6 Chinese participants' speech was inundated with these two subcategories of cohesive devices. Third, "referencing" came third reaching a total of 188 occurrences with $8.86 \%$ of frequency of use throughout the 6 participants' speech. Individual participants also displayed nearly 32 occurrences of referencing (e.g., they say) in his/her speech. Finally, the 6 Chinese participants asked a total of 58 rhetorical questions with $2.86 \%$ of frequency of use in their interactions with the 2 English native speakers. Individual participants used an average of nearly 10 rhetorical questions to signal and advance their arguments.

The use of cohesive devices in Chinese speech was done for the purpose of connecting utterances together and to achieve a certain degree of coherence in the participants' L2 speech. The data analysis revealed that the Chinese speakers not only used cohesive devices for the purpose of connecting sentences, but in some cases for adding new ideas to their interactions with the native speakers. This added function was different from the English norm of restricting the use of cohesive devices for the purpose of connecting sentences (Connor et al., 2008). For example, when a Chinese speaker introduces a new point, he/she may use the cohesive devices of "conjunction" or "disjunction" not only to connect utterances, but also to introduce new ideas that support the main point. In this case, the use of conjunction and disjunction was performed by the Chinese speaker (CS) not only to link utterances but also to push the argument forward with the native speaker (NS). For example,

CS: Yeah, and maybe one week ago, I heard on TV. It's a television program, and they have investigated some of American families, and they talk about 2019 Chinese Horoscope.

Conjunctions were the subject of a study conducted by Tang and $\mathrm{Ng}$ (1995) on Chinese students' academic writing. The study reported that these cohesive devices were highly exploited in the students' writing. On average, there were 2.56 occurrences per 100 words of text. In the present study, analysis conducted on the use of conjunction with "and" and disjunction with "but' in the Chinese students' L2 speech supported the conclusion that it was also overused in speech that reached a total of 1,875 occurrences with more than $88 \%$ frequency of use of cohesive devices. This overuse may be partly caused by the dual use of connectors not only to connect utterances but also to add new ideas to the content of their L2 speech.

The subcategory of "referencing" (e.g., they say) was commonly used by the 6 Chinese participants as a cohesive device to introduce a new topic and to provide support to their claims. For example, when a Chinese participant was asked why he came to Kuwait, he responded:

CS: It is common for college students to find opportunities to study abroad in Taiwan. They say it is good for college students to have opportunities to study abroad. So, I came here to learn Arabic.

NS: Did they justify or they just tell you?

CS: They just tell you, and they did not give any explanation.

Similarly, rhetorical questions were another cohesive device employed for adding to the propositional content of utterances. Rhetorical questions were generally employed as signaling devices or advance notices that a Chinese speaker was about to shift the topic by introducing a new idea to the conversation. In contrast, rhetorical questions in English are posed with no intention of obtaining an answer. This function is at variance with the English norm of posing rhetorical questions that require no answer (e.g., How many times do I have to tell you?). Conversely, the 6 Chinese participants were observed to pose the rhetorical question as a strategy to add new information. For 
example,

CS: Do you feel strange why now I am a senior college student but my older brother will start his undergraduate study this year? Because in our society, every adult male has to serve in the army if he does not pass the college entrance exam. He finished his military service this year, so he will start studying at the college this year.

NS: Oh. I didn't know that.

The Chinese speaker wanted to mention that her older brother, unlike her, could not go on to study in college because he needed to serve the obligatory two years in the national army. In this case, the Chinese speaker used the strategy of asking a rhetorical question to prepare the listener and to call her attention by providing a background for this new idea in their conversation.

In conclusion, both descriptive statistics and transcripts of conversations demonstrated that the primary tool that the Chinese participants relied on was the use of the four subcategories of cohesive devices that included conjunction with "and," disjunction with "but," referencing, and rhetorical questions to add points to their arguments and to present new ideas.

\subsection{L1 Influence on the Organization of Ideas}

Numerical data supported the prevalence of L1-based organization of ideas in the 6 Chinese speakers' L2 speech. Table 3 displayed the frequencies, means, percentages, and ranks of the 6 Chinese participants both as a group and as individuals for each subcategory of organization of ideas.

Table 3. Frequency of L1-based organization of ideas

\begin{tabular}{lcccc}
\hline L1-Based Organization of Ideas & Frequency & M & Percentage & Rank \\
\hline Stating One's Position at the End & 256 & 42.67 & $46.72 \%$ & 1 \\
Topic-Comment Word Order & 66 & 11.00 & $12.04 \%$ & 3 \\
Recalling & 162 & 27.00 & $29.56 \%$ & 2 \\
Revisiting & 64 & 10.67 & $11.68 \%$ & 4 \\
\hline Total & 548 & 91.34 & - & - \\
\hline
\end{tabular}

First, the subcategory of "stating one's position at the end" ranked first reaching a total of 256 occurrences with $46.72 \%$ of frequency of use as a group in the Chinese participants' L2 speech. Similarly, individual participants used "stating one's position at the end" most frequently with an average of nearly 43 occurrences. This was in contrast, however, with the cohesive devices of the conjunction with "and" and disjunction with "but" which were used with a total of 1,875 occurrences in the overall participants' speech. This indicated the primacy of conjunction and disjunction over the organization of new ideas in the Chinese participants' speech. Second, the subcategory "recalling" came second reaching a total of 162 occurrences with $29.56 \%$ of frequency of use in the participant's speech. Individual participants used "recalling" with an average of 27 occurrences as a strategy to organize their ideas. Third, the subcategory "topic-comment" sentence structure came third reaching a total of 66 occurrences with $12.04 \%$ of frequency of use in the overall participants' speech. Individual participants used "topic-comment" sentence structure with an average of 11 occurrences in their sentence structure. Finally, the subcategory "revisiting" came fourth reaching a total of 64 occurrences with $11.68 \%$ of frequency of use in the participants' speech. Individual participants used "revisiting" with nearly 11 occurrences as a strategy to organize their ideas.

Transcripts of the conversations demonstrated these subcategories of presenting new ideas in the 6 Chinese participants' speech. First, in their presentations of new ideas, the Chinese learners frequently used what may sound to an English native speaker to be long ineffective orientations before they were able to express their positions on a given topic. Data analysis revealed numerous examples of this pattern because it has been commonly used by the Chinese speakers throughout the interactions. In the following excerpt, the Chinese speaker was following a discourse strategy of presenting new ideas by first giving the reasoning behind his position right at the beginning in order to provide a sufficient background after which he was comfortable with expressing his position (in bold letters):

NS: What are they arguing about in the Taiwan's Parliament?

CS: Maybe if you are a retired teacher, solider, or government employee, you have some savings and pension for you to live on. You don't have enough money because it is expensive nowadays to live in big cities. But the government proposed to cut down the money and maybe the interest rates. They don't have money. The 
government asked the people to support the idea. So, if Parliament members want to get vote or any benefit, they even fight for the people in the Parliament.

The Chinese speaker felt the need to provide enough detail about why he was angry before reaching his point "that the parliament members are fighting for the people." In order to present his argument, the Chinese speaker was using a Chinese discourse strategy for organizing propositional information in which the main point is usually deferred until sufficient details have been provided.

Second, Chinese learners were influenced by their L1 topic-comment sentence structure. Rutherford (1983) illustrated how the information structures of L1 Chinese and L2 English have bidirectional influences in the sentence "There are so many Taiwan people live around the lake." Rutherford interpreted this sentence as L1 influence of Chinese which is a topic-prominent language. He hypothesized that Chinese learners were unconsciously organizing information following the sentence structure of their L1. Moreover, Li and Yang (2014) conducted a study on the L1 influence of Chinese topic prominence to L2 English. They found that the characteristics of Chinese topic prominent were transferrable to the interlanguage of Chinese EFL learners which meant that Chinese EFL learners gradually shifted from Chinese topic-prominence to English subject prominence. Similarly, analysis of the data of interactions collected for the purpose of the present study revealed that the structure of many sentences made by the Chinese participants followed a "topic-comment" pattern in which new information was introduced at the end of a sentence. For example,

CS: A woman pursues an advanced degree is important nowadays.

$$
\text { [Topic] [Comment] }
$$

Third, a further manifestation of the strategy of delaying the main point until sufficient detail has been made was the pattern of "recalling" which means invoking a point in the past from which the Chinese speakers linked their points to the present. For example,

CS: Many years ago, if you were just twenty, it was very common to get married. Now, it has changed. Thirty-five or forty may not be too late.

NS: Thirty-five or forty is not too late?

CS: Not too late. Now, many people get married after thirty-five.

Thus, using "recalling" something from the past was employed by the six Chinese speakers as a discourse strategy to present new ideas during their conversations with the 2 English native speakers.

Fourth, presenting a new idea was accomplished between temporally distant points of discourse. The term "revisiting" was used to describe how the Chinese speaker revisited a previously mentioned point that was not fully discussed to his/her satisfaction. The following transcript was taken from separate points in the same interactional session.

CS: We can easily buy everything in Taiwan because we have a lot of 7/11 or Family Mart. These convenience stores open 24 hours a day.

(During the first 10 minutes)

CS: If you want to have a snack or drink coffee, you can always find some things when you are hungry at night. It's easy to get in 7/11 or Family Mart.

(After 14 minutes)

CS: In Taiwan, some people like to work at night, these convenience stores will open night. Maybe the whole night they will open for customers.

(After 19 minutes)

Revisiting a previously-mentioned point in the same conversation was a strategy commonly used by the 6 Chinese speakers when they felt they have not finished talking about a point that needed more elaboration.

In sum, the Chinese discourse strategy of delaying the speaker's main point until sufficient detail has been established was followed by the Chinese participants throughout their interactions as demonstrated by the four subcategories of stating one's position at the end, topic-comment structure, recalling a point from the past, and revisiting. The subcategory of recalling a point in the past was employed by the 6 Chinese participants at the initial position which always starts at a point in the past and gradually approaches the present. Topic-comment structure is organized so that new information is included toward the end of the sentence. To a similar extent, recalling and revisiting were further manifestations of the discourse strategy of delaying the main point until enough detail has been provided by the speaker as a background to the main point. 
The L1 influenced the Chinese participants' L2 speech performance in the two areas of using cohesive devices and organization of ideas. In the category of the use of cohesive devices, four subcategories were employed by the Chinese participants: conjunction with "and," disjunction with "but," referencing, and rhetorical questions. In addition to the function of combining sentences usually performed in English discourse, the Chinese participants were influenced by the L1 in the use of cohesive devices to introduce new ideas during their interactions. The subcategory of conjunction with "and" was the most frequently employed cohesive device in the Chinese participants' speech followed by disjunction with "but," referencing, and rhetorical questions. In the category of organization of ideas, four L1-based subcategories were observed in the Chinese participants' speech with the most frequently-used subcategory of "stating one's position at the end." The data of the interactions revealed that the sentence level "topic-comment" structure was employed by the 6 Chinese participants. Extended analyses of the data of interactions beyond the sentence level additionally revealed the two patterns of "recalling" a point from the past, and "revisiting" a previously-mentioned point. These two subcategories were employed whenever a Chinese speaker organized language to provide sufficient detail before a main point was articulated.

\section{Implications for Pedagogy}

The researchers recommend the creation of a learning environment in the language classroom in which relations are established between specific L1-L2 discourse patterns. Van Lier (1996) suggested that "innovative ways can be found of playing L1 and L2 off against one another productively" (p. 19). For example, teachers can create scaffolding tasks in which Chinese students can be encouraged to compare and contrast between the English and Chinese ways of arguing a point, debating an issue, and presenting support to an argument in spoken as well as written discourse. In the absence of continuous exposure to L1-L2 relations within the confines of the classroom, Chinese learners who engage in actual communication with native speakers of the target language are bound to exhibit L1 influence effects similar to those observed in the L2 speech of the Chinese participants in the current investigation. Teachers can play a crucial role in the learners' understanding of L1-L2 relations. They can conduct action research to scrutinize the effectiveness of research recommendations in the classroom. Armed with evidence from the classroom, teachers can investigate the potential success of providing opportunities for their students to investigate and report on particular areas of L2 discourse (e.g., rhetorical organization) as well as making comparisons between their own L1 discourse and corresponding discourse patterns of the target language. Students need to be given the opportunity by their teachers to construct their own interpretations of how to interact successfully with native speakers of English. Finally, with increased access to the Internet, Chinese students can use technology to conduct independent projects on specific aspects of American discourse (e.g., persuasion in TV commercials, debates, interviews, etc.) and report back to their classrooms.

\section{Implications for Research}

More research on the phenomena of L1 influence in the L2 speech of Chinese EFL learners is needed to create a database of points of difference and similarity between the L1 and L2 in the areas of cohesive devices and organization of ideas. Moreover, since English has established itself as the world's language of wider communication, more research studies are needed that focus on the L2 spoken performance of speakers from other languages in order to investigate the language-specific ways of organizing ideas and cohesive devices that may lead to communication difficulties between English native speakers and EFL learners from other language backgrounds. Syllabus designers and materials writers can also choose examples from these databases to expose their students to negative, positive, and neutral cases of L1 influence.

\section{References}

Bardovi-Harlig, K., \& Hartford, B. S. (2016). Interlanguage pragmatics: Exploring institutional talk. New York: Routledge.

Connor, U., Nagelhout, E., \& Rozycki, W. V. (Eds.). (2008). Contrastive rhetoric: Reaching to intercultural rhetoric. Philadelphia, PA: John Benjamins Publishing. https://doi.org/10.1075/pbns.169

Corbin, J., \& Strauss, A. (2015). Basics of Qualitative Research. Thousand Oaks, CA: Sage.

Ellis, R. (2012). Language teaching research and language pedagogy. Malden, MA: Wiley-Blackwell. https://doi.org/10.1002/9781118271643

Gibbs, G. R. (2018). Analyzing qualitative data (2nd ed.). London: SAGE.

Golden, A., Jarvis, S., \& Tenfjord, K. (Eds.). (2017). Crosslinguistic influence and distinctive patterns of language learning: Findings and insights from a learner corpus. Blue Ridge Summit, PA: Multilingual Matters. 
Lantolf, J. P., \& Poehner, M. E. (2014). Sociocultural theory and the pedagogical imperative in L2 education: Vygotskian praxis and the research practice divide. New York: Routledge. https://doi.org/10.4324/9780203813850

Li, S., \& Yang, L. (2014). A discourse perspective of topic-prominence in Chinese EFL learners' interlanguage. International Journal of Applied Linguistics and English Literature, 3(4), 190-197. https://doi.org/10.7575/aiac.ijalel.v.3n.4p.190

McKay, S. L., \& Wong, S. L. C. (1996). Multiple discourses, multiple identities: Investment and agency in second-language learning among Chinese adolescent immigrant students. Harvard Educational Review, 66(3), 577-609. https://doi.org/10.17763/haer.66.3.n47r06u264944865

Mohamed-Sayidina, A. (2010). Transfer of L1 cohesive devices and transition words into L2 academic texts: The case of Arab students. RELC Journal, 41(3), 253-266. https://doi.org/10.1177/0033688210380569

Odlin, T. (1989). Language transfer: Cross-linguistic influence in language learning. New York: Cambridge University Press. https://doi.org/10.1017/CBO9781139524537

Odlin, T., \& Yu, L. M. (2016). Introduction. In L. Yu \& T. Odlin (Eds.), New perspectives on transfer in second language learning (pp. 1-16). Bristol: Multilingual Matters.

Peirce, B. N. (1995). Social identity, investment, and language learning. TESOL Quarterly, 29(1), 9-31. https://doi.org/10.2307/3587803

Pasquarella, A., Chen, X., Lam, K., Luo, Y. C., \& Ramirez, G. (2011). Cross - language transfer of morphological awareness in Chinese-English bilinguals. Journal of Research in Reading, 34(1), 23-42. https://doi.org/10.1111/j.1467-9817.2010.01484.x

Ritchie, W. C., \& Bhatia, T. K. (2013). The handbook of second language acquisition (2nd ed.). Leiden Boston: Brill.

Rutherford, W. (1983) Language typology and language transfer. In S. Gass \& L. Selinker (Eds.), Language transfer in language learning (pp. 358-370). Rowley, MA: Newbury House.

Scollon, R., Scollon, S. W., \& Jones, R. H. (2012). Intercultural communication: A discourse approach. Malden, MA: Wiley-Blackwell.

Selinker, L., \& Rutherford, W. E. (Eds.). (2014). Rediscovering interlanguage. New York: Routledge.

Tang, E., \& Ng, C. (1995). A study on the use of connectives in ESL students' writing. Perspectives, 7(2), 105122. http://sunzil.lib.hku.hk/hkjo/view/10/1000093.pdf

Ting, S. H., \& Lau, L. Y. (2008). Lexical and discourse-based communication strategies of Malaysian ESL Learners. Malaysian Journal of ELT Research, 4(1), 18-31. Retrieved from http://www.melta.org.my

Van Lier, L. (1996). Interaction in the language curriculum: Awareness, autonomy and authenticity. New York: Longman.

\section{Copyrights}

Copyright for this article is retained by the author(s), with first publication rights granted to the journal.

This is an open-access article distributed under the terms and conditions of the Creative Commons Attribution license (http://creativecommons.org/licenses/by/4.0/). 